\title{
ANALISIS MARGIN PEMASARAN SEMANGKA MADU DI KECAMATAN RETEH KABUPATEN INDRAGIRI HILIR
}

\author{
Yeni Afiza, Gunawan Syahrantau \\ Program Studi Agribisnis Fakultas Pertanian UNISI \\ Email : Yeni_afiza@yahoo.co.id
}

\begin{abstract}
ABSTRAK
Tujuan penelitian ini adalah : (1) untuk mengetahui margin pemasaran semangka madu di Kecamatan Reteh Kabupaten Indragiri Hilir, (2) Untuk mengetahui farmer's share pemasaran semangka madu di Kecamatan Reteh Kabupaten Indragiri Hilir dan (3) Untuk mengetahui efesiensi pemasaran semangka madu di Kecamatan Reteh Kabupaten Indragiri Hilir. Metode penelitian yang digunakan yaitu (1) margin pemasaran (2) farmer's share dan (3) efesiensi pemasaran. Hasil penelitian adalah : (1) margin pemasaran saluran 1 tidak ada, margin pemasaran saluran 11 sebesar Rp 2.000,- per kg dan margin pemasaran saluran 111 sebesar Rp 4.000.- per kg, (2) farmer's share saluran 1 sebesar $100 \%$, farmer's share saluran 11 sebesar 75\% dan farmer's share saluran 111 50\%, (3) Efesiensi saluran 1 sebesar $0,41 \%$, saluran 11 sebesar $0,42 \%$ dan saluran 111 yaitu $1,02 \%$.
\end{abstract}

\begin{abstract}
The purpose of this research are : (1) to find out the marketing margins of watermelon honey in thevillage after the sub-district period reteh Indragiri Hilir district, (2) to find out the farmer's share of watermelon honey in the village after the sub-district period reteh Indragiri Hilir district, and (3) to find out the marketing efficiency of watermelon honey in the village after the sub-district period reteh Indragiri Hilir district. The research method used is (1) marketing margin (2) farmer's share and (3) marketing efficiency. The results of the study are : (1) channel I marketing margin does not exist, channel marketing margin II of Rp 2.000,- per kg, and channel marketing margin III of Rp 4.000,- per kg, (2) farmer's share channel I of $100 \%$, farmer's share channel II of 75\%, and farmer's share channel III of 50\%, (3) channel efficiency I of $0,41 \%$, channel efficiency II $0,42 \%$ and channel III is $1,02 \%$.
\end{abstract}

\section{PENDAHULUAN}

Pemasaran komoditi pertanian Indonesia merupakan bagian yang paling lemah dalam mata rantai perekonomian. Hal ini berarti efisiensi dibidang pemasaran masih rendah sehingga kemungkinan untuk mempertinggi tingkat efisiensi masih besar (Mubyarto, 1995).

Pemasaran merupakan faktor yang sangat penting dalam dunia usaha, tanpa danya suatu pemasaran maka pendistribusian produksi hasil olahan maupun pertanian akan terhambat atau tidak sampai pada konsumen ataupun sasaran yang dituju. 
Untuk itulah pemasaran sangat penting untuk mewujudkan pembangunan pertanian Indonesia.

Aspek pemasaran memang penting bila mekanisme pemasaran berjalan baik, maka semua pihak yang terlibat akan diuntungkan. Oleh karena itu peranan lembaga pemasaran yang biasanya terdiri dari produsen, tengkulak, pedagang besar, eksportir atau lainnya menjadi amat penting. Lembaga pemasaran ini, khususnya bagi Negara berkembang, yang dicirikan oleh lemahnya pemasaran hasil pertanian, akan menentukan mekanisme pasar (Soekartawi, 2001).

$$
\text { Saptana et.,al., (2010), }
$$

menyatakan bahwa komoditas hortikultura merupakan komiditas potensial yang mempunyai nilai ekonomi tinggi dan memiliki potensi untuk terus dikembangkan. Salah satu jenis buah yang mudah dipasarkan adalah semangka madu, pemasaran semangka madu yang ada di Kecamatan Reteh saat ini cukup baik dan menjanjikan, karena sebagian besar masyarakat melakukan budidaya semangka madu.

Berdasarkan hasil tinjauan pada petani pemasaran buah semangka madu hanya dihargai Rp.4.000 perkilonya jika dibeli konsumen secara langsung pada petani. Sedangkan harga dipasar mencapai Rp.8.000 perkilonya. Hal ini mengakibatkan penerimaan yang diterima petani relatife rendah karena harga jual dari petani sangat rendah. Pihak yang paling diuntungkan dalam hal ini adalah pedagang yang ada di level tengah, seperti pedagang besar. Karena ada ketidakseimbangan dalam harga jual di tingkat petani dengan pedagang, maka terdapat celah harga yang relatif sangat besar. Tujuan penelitian ini adalah : 1) Untuk mengetahui marjin pemasaran semangka madu, 2) Untuk mengetahui farmer share pemasaran semangka madu, dan 3) Untuk mengetahui efisiensi pemasaran semangka madu di Kecamatan Reteh Kabupaten Indragiri Hilir.

\section{METODOLOGI PENELITIAN}

\subsection{Lokasi dan Waktu Penelitian}

Penelitian ini dilakukan di Kecamatan Reteh Kabupaten Indragiri Hilir. Pemilihan tempat dilakukan secara sengaja (purposive) berdasarkan pertimbangan bahwa Kecamatan Reteh merupakan salah satu sentra produksi semangka madu di Kabupaten Indragiri Hilir. Penelitian ini dilakukan pada bulan Januari hingga April 2019.

\subsection{Metode Pengambilan Sampel}

Metode yang digunakan untuk menentukan sampel petani semangka madu adalah metode purposive random sampling (acak sederhana), yaitu sebuah bentuk metode sampel yang diambil sedemikian rupa sehingga tiap unit penelitian atau satuan elemen dari populasi mempunyai kesempatan yang sama untuk dipilih menjadi sampel penelitian. (Singarimbun dan Effendi 2008). Metode acak sederhana dilakukan karena populasi dalam penelitian ini bersifat homogen. Besar sampel yang didapat adalah sebanyak 30 orang.

Sedangkan untuk menentukan sampel pedagang semangka madu adalah dengan menggunakan metode snowball sampling (bola salju), yaitu dengan menemui beberapa orang pedagang semangka madu untuk menunjuk sampel berikutnya yang 
sesuai dengan karakteristik yang dibutuhkan dalam penelitian ini. penelitian iini adalah pemasaran buah Karakteristik yang dibutuhkan dalam semangka madu.

Jumlah populasi dan sampel yang dibutuhkan dalam penelitian ini disajikan pada tabel 1 .

Tabel 1. Jumlah populasi dan sampel yang dibutuhkan

\begin{tabular}{|c|l|c|}
\hline No & \multicolumn{1}{|c|}{ Subjek Penelitian } & Sampel (jiwa) \\
\hline 1 & Petani & 30 \\
\hline 2 & Pedagang besar & 6 \\
\hline 3 & Pengecer & 8 \\
\hline
\end{tabular}

\subsection{Metode Analisis Data}

Untuk menganalis data penulis menggunkan analisis kuantitatif dan deskriptif, yang mana data yang telah dikumpulkan didalam penelitian dikumpulkan dan dikelompokkan menurut jenisnya. Kemudian data tersebut dianalisis dengan menghubungkan dengan landasan teori yang telah diuraikan dalam tinjauan pustaka untuk selanjutnya di ambil kesimpulan. Metode analisis data yang digunakan dalam penelitian ini adalah :

\subsubsection{Marjin Pemasaran}

Tingkat efisiensi operasional suatu tataniaga dapat dilihat dari penyebaran marjin tataniaga, farmer's share serta rasio keuntungan dan biaya. Melalui marjin tataniaga dapat diketahui besarnya biaya dan keuntungan dalam tataniaga tersebut. Bersamaan dengan penelusuran saluran tataniaga diharapkan dapat diperoleh informasi tentang marjin tataniaga pada tiap lembaga tataniaga. Perhitungan marjin tataniaga diperoleh dari selisih harga di satu titik rantai tataniaga dengan harga di titik lainnya. Selain itu, besarnya nilai marjin tataniaga juga dapat diperoleh dari penjumlahan biaya dan keuntungan pada masing-masing lembaga tataniaga. Menurut Limbong dan Sitorus (1987), secara matematik akan diperoleh perhitungan sebagai berikut:

$$
\begin{aligned}
& \mathrm{Mi}=\mathrm{Pi}-\mathrm{Pi}-1 \\
& \mathrm{Mi}=\mathrm{Bi}+\pi \mathrm{I} .
\end{aligned}
$$

Dengan demikian,

$$
\mathrm{Pi}-\mathrm{Pi}-1=\mathrm{Bi}+\pi \mathrm{I}
$$

Maka besarnya marjin tataniaga dengan menggunakan (1) dan (2) adalah sebagai berikut:

$$
\mathrm{mi}=\Sigma \mathrm{Mi}
$$

Dengan demikian keuntungan lembaga tataniaga pada tingkat ke-i adalah : $\pi \mathrm{i}=\mathrm{Pi}-\mathrm{Pi}-1+\mathrm{Bi}$

\section{Keterangan:}

$\mathrm{Mi}=$ Marjin pada lembaga tataniaga ke-i

$\mathrm{Pi}=$ Harga penjualan pada lembaga tataniaga ke-i

Pi-1 =Harga penjualan pada lembaga tataniaga ke-i atau harga pembelian pada lembaga tataniaga ke-i

$\mathrm{Bi}=$ Biaya tataniaga pada lembaga tataniagake-i

$\pi \mathrm{I} \quad=$ Keuntungan yang diperoleh 
pada lembaga tataniaga ke-i

mi $\quad=$ Total marjin tataniaga

Dalam pasar persaingan sempurna, perjalanan suatu produk selalu melibatkan banyak lembaga tataniaga. Marjin tataniaga total yang terjadi merupakan penjumlahan marjin tataniaga dari setiap lembaga tataniaga.

\subsubsection{Farmer's Share}

Indikator lain untuk menentukan efisiensi operasional tataniaga suatu komoditas adalah melalui perhitungan farmer's share. Farmer's share berhubungan negatif dengan marjin tataniaga. Farmer's share dipengaruhi oleh tingkat pengolahan, keawetan produk, ukuran produk, jumlah produk, dan biaya produksi. Nilai farmer's share ditentukan oleh besarnya rasio harga yang diterima produsen (Pf) dan harga yang dibayarkan oleh konsumen (Pr).

Secara matematik dapat dirumuskan dengan persamaan sebagai berikut (Dahl \& Hammond 1977):

$$
\mathrm{F} s=\frac{P_{f}}{P_{r}} \times 100 \%
$$

Keterangan :

$F s=$ Farmer's share

$P f=$ Harga di tingkat petani

$\operatorname{Pr}=$ Harga di tingkat konsumen

\subsubsection{Efisiensi Pemasaran}

Konsep efisiensi merupakan konsep yang mendasar dan lahir dari konsep ekonomi. Meskipun demikian, konsep mengenai efisiensi dapat didefinisikan dari berbagai sudut pandang dan latar belakang. Pada umumnya, efisiensi dapat diarahkan kepada sebuah konsep tentang pencapaian suatu hasil dengan penggunaan sumber daya secara optimal. Efisiensi pemasaran dihiutng dengan rumus berikut:

$\mathrm{EP}=\frac{\mathrm{TBP}}{\mathrm{TNP}} \times 100 \%$

Keterangan :

Ep = Efisiensi pemasaran

TBP = Total biaya pemasaran

TNP =Total nilai produk yang dibeli konsumen

Menurut (Hanafiah, 1983)

Syarat efisiensi sistem pemasaran ada tiga yaitu:

a) Jarak antara produsen dan konsumen, semakin jauh jarak antara produsen dan konsumen biasanya makin panjang saluran yang ditempuk oleh produk.

b) Cepat tidaknya produk rusak, produk yang cepat atau mudah rusak harus segera diterima konsumen dan dengan demikian menghendaki saluran yang pendek dan cepat.

c) Skala produksi, apabila produksi berlangsung dalam ukuran-ukuran kecil maka jumlah produk yang dihasilkan berukuran kecil pula, hal mana akan tidak menguntungkan bila produsen langsung menjualnya ke pasar. Dalam keadaan demikian kehadiran pedagang perantara diharapkan dan dengan demikian saluran yang akan dilalui produk cenderung panjang. 
III. HASIL DAN PEMBAHASAN

3.1. Saluran Pemasaran Semangka Madu

Berdasarkan hasil penelitian dilapangan menunjukan bahwa di Kecamatan Reteh memiliki tiga saluran. Secara umum saluran pemasaran buah semangka di
Desa Reteh Lama Kecamatan Reteh melibatkan lembaga pemasaran seperti pengumpul (tengkulak), pedagang besar, pedagang pengecer.

Untuk mengetahui lebih jelas saluran pemasaran buah semangka di Kecamatan Reteh dapat dilihat pada gambar 1, 2 dan 3 .

\section{Saluran pemasaran I.}

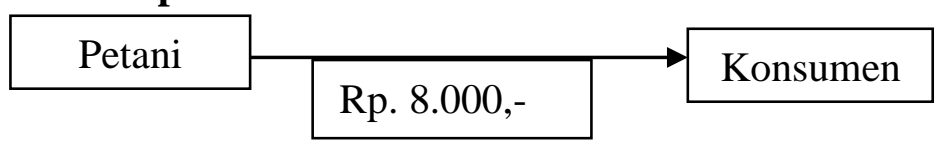

\section{Gambar 1. Saluran Pemasaran I}

Saluran pemasaran I kepada konsumen dengan harga menjelaskan bahwa harga jual buah Rp.8.000,- perkilonya. semangka madu yang dijual langsung

Saluran pemasaran II.

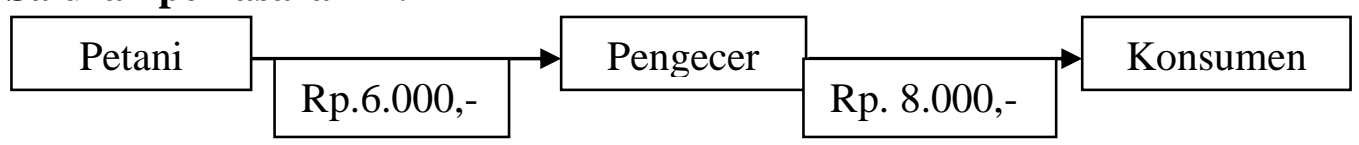

Gambar 2. Saluran Pemasaran II

Saluran pemasaran II menjelaskan bahwa harga jual buah semangka madu yang dijual langsung petani kepada pengecer dengan harga
Rp. 5.000,- kemudian pengecer menjual kepada konsumen dengan harga Rp.8.000,- perkilonya.

Saluran pemasaran III.

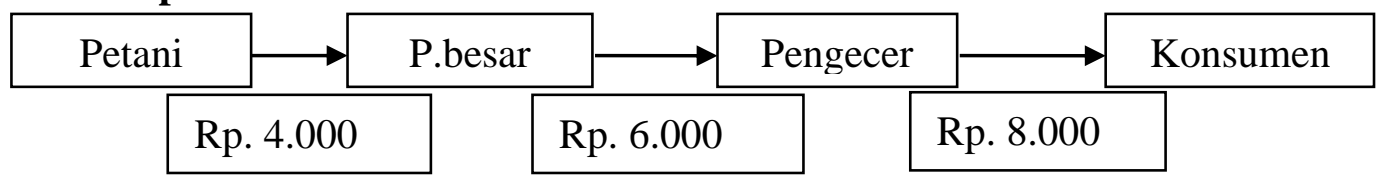

Gambar 3. Saluran Pemasaran III

Saluran pemasaran III bagan menjelaskan harga jual buah semangka madu kepada pedagang besar dengan harga Rp.4.000,- kemudian pedagang besar besar menjaul kepada pengecer dengan harga Rp. 6.000,- kemudian pengecer menjual kepada konsumen dengan harga Rp.8.000,- perkilonya. 


\subsection{Margin pemasaran}

Menurut Ratya, (2004) Marjin pemasaran merupakan perbedaan harga di antara tingkat lembaga dalam sistem pemasaran, atau perbedaan antara jumlah yang dibayar konsumen dengan jumlah yang diterima produsen atas suatu produk pertanian yang diperjual belikan pada waktu, volume, dan kualitas yang sama. Margin pemasaran semangka madu di Kecamatan Keritang dapat dilihat pada Tabel 2.

Tabel 2. Margin Pemasaran Semangka Madu di Kecamatan Keritang

\begin{tabular}{|c|l|r|}
\hline No & \multicolumn{1}{|c|}{ Jenis Saluran } & \multicolumn{1}{|c|}{ Jumlah Margin (Rp) } \\
\hline 1 & Saluran I & $2.000,00$ \\
\hline 2 & Saluran II & $4.000,00$ \\
\hline 3 & Saluran III & \\
\hline
\end{tabular}

Sumber : Data primer diolah, 2019

Pada penelitian ini besarnya margin saluran I adalah 0, karena untuk petani langsung menjual buah semangka kepada konsumen. Besarnya margin pemasaran pada saluran II adalah sebesa Rp. 2,000.00 per $\mathrm{Kg}$ dan pada saluran III adalah sebesar Rp.4,000.00 per $\mathrm{Kg}$, hal ini dikarenakan pada saluran II dan III harus melewati beberapa saluran lagi.

Pemasaran dengan tujuan pedagang pengecer ke pasar Reteh tidak terlalu mempermasalahkan grading, semua ukuran semangka diterima oleh pedagang pengecer asalkan buah semangka dalam kondisi baik, tidak ada cacat/busuk. Varietas yang digunakan dalam penelitian ini tidak berpengaruh terhadap harga, karena varietas yang digunakan samasama semangka madu, yang membedakan harga buah semangka yaitu dari segi ukuran buah.

\subsection{Farmer's Share}

Margin pemasaran dapat digunakan untuk mengetahui bagian harga untuk petani (farmer's share). Besarnya margin pemasaran dipengaruhi oleh besarnya bagian biaya dan keuntungan lembaga pemasaran. Farmer's share pemasaran semangka madu di Kecamatan Reteh dapat dilihat pada Tabel 3.

Tabel 3. Farmer's Share Pemasaran Semangka Madu di Kecamatan Keritang

\begin{tabular}{|l|l|r|}
\hline No & \multicolumn{1}{|c|}{ Jenis Saluran } & Farmer's Share (\%) \\
\hline 1 & Saluran I & 100,00 \\
\hline 2 & Saluran II & 75,00 \\
\hline 3 & Saluran III & 50,00 \\
\hline
\end{tabular}

Sumber : Data primer diolah, 2019

Berdasarkan tabel 3 menunjukan farmer's share terbesar terdapat pada saluran I yaitu sebesar 100 persen. Pada saluran II yaitu sebesar 75 persen dari harga jual ratarata di tingkat konmsumen. Sedangkan pada saluran III besarnya farmer's share adalah 50 persen dari harga jual rata-rata tingkat konsumen. 


\subsection{Efisiensi Pemasaran}

Efisiensi pemasaran dapat dihitung dengan biaya pemasaran dibagi dengan nilai produksi yang dipasarkan, kemudian dikalikan dengan 100 persen dan ini disebut dengan Ep. Makin kecil Ep semakin efisiensi pemasaran itu. Nilai efesiensi pemasaran semangka madu di Kecamatan Reteh dapat dilihat pada Tabel 4.

Tabel 4. Efesiensi Pemasaran Semangka Madu di Kecamatan Keritang

\begin{tabular}{|c|l|r|}
\hline No & \multicolumn{1}{|c|}{ Jenis Saluran } & Farmer's Share (\%) \\
\hline 1 & Saluran I & 0,41 \\
\hline 2 & Saluran II & 0,42 \\
\hline 3 & Saluran III & 1,02 \\
\hline
\end{tabular}

Sumber : Data primer diolah, 2019

Pada penelitian ini saluran yang paling efisien terdapat pada saluran I dengan nilai 0,41 karena nilai efisien lebih kecil dibandingkan dengan saluran yang lainnya. Pada saluran I persentase biaya yang dikeluarkan relatif kecil apabila dibandingkan dengan saluran pemasaran lainnya disebabkan karena saluran I dalam pemasaran semangka madu di Kecamatan Reteh tidak melibatkan lembaga pemasaran, yang berperan dalam memasarkan hasil panen semangka madu tersebut adalah petani sendiri. Dan pada saluran I posisi tawar menawar lebih kuat dibandingkan dengan saluran pemasaran lainnya karena petani itu sendiri yang menjual hasil panennya ke konsumen sehingga harga jual buah semangka madu yang diterima oleh petani lebih tinggi.

\section{KESIMPULAN DAN SARAN 4.1 Kesimpulan}

1. Saluran pemasaran buah semangka madu di Kecamatan Reteh Kabupaten Indragiri Hilir yaitu saluran I petani ke konsumen, saluran II petani ke pedagang pengecer ke konsumen dan saluran III petani ke pedagang besar ke pedagang pengecer ke konsumen.

2. Pada saluran I margin pemasaran tidak ada. Besarnya margin pemasaran pada saluran II adalah sebesa Rp. 2,000.00 per Kg dan pada saluran III adalah sebesar Rp.4,000.00 per Kg.

3. Farmer's share pada saluran I adalah sebesar $100 \%$ dan pada saluran II 75\% sedangkan pada saluran III besarnya farmer's share adalah $50 \%$.

4. Saluran I merupakan saluran pemasaran yang paling efisien dengan Ep $0.41 \%$ kemudian diikuti dengan saluran II dengan Ep sebesar $0.42 \%$ dan efisiensi pada saluran III yaitu sebesar $1,02 \%$.

\subsection{Saran}

1. Petani disarankan menjual langsung buah semangka madu ke konsumen tanpa melalui lembaga pemasaran sehingga harga buah semangka madu menjadi lebih tinggi dan keuntungan petani lebih tinggi.

2. Perlu pengembangan media informasi harga sampai tingkat petani, misalnya melalui penyuluh pertanian. Informasi 
harga diharapkan dapat membantu petani dalam merencanakan dan menentukan harga buah semangka madu.

\section{DAFTAR PUSTAKA}

Arifin Zainal. 1997. Evaluasi Pemasran. Remadja Karya. Bandung.

Ariyantoro. H. 2006. Budi Daya Tanaman Perkebunan. Pustaka Pelajar. Jakarta

Anonimous. 2012. Prinsip Dasar Ilmu Gizi. PT Gramedia Pustaka Utama. Jakarta.

Bambang. 2006. Metode Penelitian. Pustaka Indonesia. Yogyakarta

Basu Swasta dan Irawan. 1999. Manajemen Pemasaran Modern. Liberty. Yogyakarta

Basu Swastha dan Hani Tani Handoko. 2004. Perilaku Konsumen Teori dan Penerapannya dalam Pemasaran. YEPP. Bogor

David Cravens. 1997. Pemasaran Strategis Jilid 1 . Balai Pustaka. Jakarta

Depdikbud. 1990. Identitas Masyarakat Indonesia. Balai Pustaka. Jakarta.

Dimyati. 2009. Marketing Edisi Baru. Media Pressindo. Yogyakarta

Duljapar dan Setyowati. 2000. Semangka. Pustaka Pelajar. Jakarta.
Hendra Teguh dan Roni A. Rusli. 1999. Manajemen Pemasaran. Liberty. Yogyakarta.

Irawan.2001. Manajemen Pemasaran Modern.Edisi Kedua. PT. Gramedia. Jakarta

Jordan Manggopa, Skripsi, Efesiensi pemasaran nanas di Lobong Kecamatan Passi L...... Kabupaten Bolaang Mongondow, 2013.

Kuma'at. R. (1992). Sistem Pemasaran Ssayuran Dataran Tinggi di Provinsi Sulawesi. PT. Gramedia. Jakarta

Lida Noer, Skripsi, Analisis pendapatan dan pemasaran usaha tani semangka madu di desa Maranatha Kecamatan Sigi Biromaru Kabupaten Sigi, 2014

Mubyarto. 1995. Pengantar Ekonomi Pertanian. PT. Pustaka LP3ES Indonesia. Jakarta

Nudiyah, Skripsi, analisis pemasaran jambu mete di Kabupaten Muna Provinsi Sulawesi Tenggara,2014

Ratya Anindita. 2004. Pemasaran Hasil Pertanian. Papyrus. Surabaya

Rukmana Rahmat. 2000. Pemasaran Produk Pertanian. USU Press. Medan.

Saragih, $\quad$ B. 2001. Agribisnis Paradigma Baru Pembangunan Ekonomi Berbasis Pertanian. Pustaka Wirausaha Muda. Jakarta. 
